\title{
Fluorine F 18-fluoroazomycin Arabinoside
}

National Cancer Institute

\section{Source}

National Cancer Institute. Fluorine F 18-fluoroazomycin Arabinoside. NCI Thesaurus.

Code C62520.

A radiofluorinated 2-nitroimidazole derivative with positron-emitting radioisotope activity. Upon administration, fluorine F 18-fluoroazomycin arabinoside is reduced under hypoxic conditions in the tumor microenvironment to a reactive species that covalently binds to intracellular macromolecules, providing a quantitative measure of viable hypoxic tissue when imaged with positron emission tomography. Compared to 18F-misonidazole, fluorine F 18-fluoroazomycin arabinoside has a lower octanol:water partition coefficient; it therefore has less tendency to accumulate in lipophilic tissues and exhibits a faster renal clearance, which may result in improved imaging of hypoxic tissue. 